\title{
Innovative technologies in construction and Building Information Modeling
}

\author{
Ella Okolelova ${ }^{1, *}$, Marinna Shibaeva ${ }^{1}$, Natalya Trukhina ${ }^{1}$, and Oksana Konitskaya ${ }^{1}$ \\ ${ }^{1}$ Voronezh State Technical University, Moscow Avenue, 14, Voronezh, 394026, Russia
}

\begin{abstract}
The paper presents the results of research in the field of the use of innovative technologies in the design of buildings. The modern technologies of information modeling, in particular, BIM, which makes it possible to represent the building not only in three-dimensional space, but also allows designing it in the dynamic system « design - construction operation » are considered. The experience of using BIM technologies is based on identifying errors at the initial design stage and the possibility of their elimination at the same stage. The development of mechanisms for detecting design errors and defects formed the basis of the task set in the work. A model for signaling about the detection of defects has been developed, and the problem of stochastic modeling of the qualitative parameters of the designed object has been solved.
\end{abstract}

\section{Introduction}

Design and construction has always evolved. Not so long ago, engineers used drawings flat projections. Then layouts appeared. The idea of the building became much clearer, but engineering communications were not visible in the layout, there was no technical component of the project.

Then it was time for the computer-aided design - AutoCad. The information about the object was much more voluminous, but when the speed of information and the requirements for detailed study and design of buildings increased to modern rates, the era of BIM technologies began.

The development of information technology in design began in the 80s of the last century. In 1976, the first program was proposed, according to which it was possible to assemble a building from specific architectural elements. The program made it possible to add such parameters as the material for the manufacture of structures.

In 1986, GMW pioneered the concept of phased construction, which greatly helped in the construction of the third terminal at Heathrow Airport in London.

The term Building Information Modeling first appeared in 1992. The exchange and compatibility of information in digital format made it possible to create not only a threedimensional building format, but also to build a dynamic object model focused on tracking and analyzing the entire life cycle.

\footnotetext{
*Corresponding author: Ella.o2011@yandex.ru
} 
In modern construction, BIM is a project architecture, but the architecture is dynamic, easily transformable for any changes in requirements or conditions.

BIM involves the creation of a spatial 3D model, followed by filling it with architectural, engineering, technological, economic and other information about a building with all interconnections and dependencies. As a result, all structural elements and components are considered as a single object.

BIM (Building Information Modeling) is information modeling of a building, which determines the whole process of creating some "twins" of the modeled object, which takes into account the filling of information about the object itself and all stages of its life cycle.

The emergence of digital models is directly related to the development of information technology. If earlier it seemed impossible to bring together all the information about the project (architectural, engineering, operational, commercial), now it has become a reality. Each project carried out with the use of BIM technologies is a combination of an architectural project, technical documentation, a detailed construction schedule. This is a detailed analysis and accurate calculation of the building at all stages of its creation. This is predicting its performance. A system of aggregate characteristics of an object is formed both in statics and in dynamics.

BIM is the ability to manage the construction, operation, restoration, renovation and even demolition of a building. In addition, BIM design is a collective process in which representatives of various departments and services take part.

BIM is a huge database. It is all numerical and properly organized information about an object used for design, construction and subsequent operation of a building, a new principle for collecting and processing information.

\section{Materials and Methods}

In information modeling, a virtual computer model is created, where each element of the model is described not only by its geometry and its position in space, but also by a set of attribute information.

An important thing in information modeling is that a BIM model that visualizes an object in 3D allows tracking the dynamics of its construction and operation. Design errors, if any, can be tracked and corrected at this stage. In other words, designers can see an object in the future, at the stage of not only construction, but also operation, when errors and design errors can manifest themselves and cause serious damage.

BIM is not limited to architecture and engineering solutions of a building and is not a model of a building or its individual parts [1]. BIM also may not be limited to individual building models. This model can include design surfaces, utility models, roads, and other infrastructure and landscape elements.

Information modeling technologies are especially relevant for industrial facilities, where the presence of specialized technological equipment is assumed. In this case, the technology of information modeling of an object involves its use not only at the design stage, but also at the construction stage. For the design and construction of industrial enterprises, it is important that all management decisions are based on the availability of technological lines and equipment. The reality is that the design and production of technological lines is often carried out outside the Russian Federation. Therefore, communication between specialists performing general construction work and designing technological solutions is sometimes not always possible.

In this case, BIM comes to the rescue. There are cloud information systems that allow building a model of an object as close as possible to the real conditions of the object's functioning in a short time. This not only shortens the construction time of the facility, but also significantly reduces costs. 
Drawings, which were previously used in the design of buildings, contained many errors. But the main problem of using them was not only the presence of errors, but the fact that these errors were transferred to the constructed object, and it was almost impossible to fix them. Many defects were detected already during the operation of the building.

Today, design is carried out not just in a 3D modeling system, but in information modeling. It is not just the building envelope that is modeled. A modern model is an object with information contained within, and this information is dynamic, subject to deep and comprehensive analysis by specialists and can reveal existing or expected defects at any time.

Information can be generated in two ways. The first way - the object is created by the user himself and fills him with the necessary information. The second method, the most economical for the user, is to create elements from the library. These libraries are used to convey complex technical information, since any model is a complex technical product. The point of creating a three-dimensional model is that when one element changes, the model changes almost all parameters, including the main elements and the building node, as well as the economic calculations of the project.

BIM is usually differentiated into the following stages:

- BIM of the zero level involves the development of a 2D model;

- BIM of the first level - 2D model with separate 3D elements;

- BIM of the second level - 3D modeling and model coconstruction through data export;

- BIM of the third level is a fully integrated unified environment in construction and management.

It is believed that the BIM model completely eliminates design errors, which is not entirely true. Mistakes are possible, and sometimes very serious. At the same time, the main feature of the BIM model is that it allows you to see the consequences of these errors at the stage of project creation and eliminate them in time [2].

In addition, information modeling leads to the transparency of the implementation of a complex technological system «design - construction - operation » both in terms of the specification of internal engineering equipment, production technology, and in terms of costs.

Experts note that in standard design, labor costs are divided as follows:

- $\quad 30 \%$ - looking for engineering solutions;

- $10 \%$ - for approval and adoption of design solutions;

- $60 \%$ - for the design and issue of project documentation.

When changes are made to design solutions, the costs of re-approval, processing and alteration of the design documentation itself increase significantly. BIM technology is fundamentally changing the ratio of labor costs relative to traditional design technologies. The creation of an object using BIM technology allows one to highly automate the process of preparing and issuing project documentation.

As the experience of foreign countries shows, the use of BIM reduces the cost of construction by an average of $30 \%$. This is a colossal amount in terms of the cost of designing and constructing buildings.

Information modeling is very important in terms of understanding the collision of engineering networks when it comes to their possible intersection. BIM allows seeing the designer's mistakes and adjusting the working conditions.

The basis of the work of the BIM-design system should be based on the principle of predicting the appearance of defects. This process in the full sense of the word can become a quality management system and ensure minimal losses during the construction of a building [3].

\section{Results}


The main topic of information modeling remains the issue of operational assessment of the design quality and timely elimination of defects. BIM makes it possible to do this by tracing the entire life cycle of a building in the interaction of all engineering systems and structural elements.

The task of modeling is the timely identification of errors, inaccuracies and defects arising at the design stage, and the fastest possible response to their elimination.

Information modeling should be based on a quality assessment system, which consists in the timely tracking of signals about defects and their correction [4].

The system of receipt of signals about the presence of a defect at a separate level in the system and their subsequent processing will be presented in the form of a spatial model (Fig. 2.).

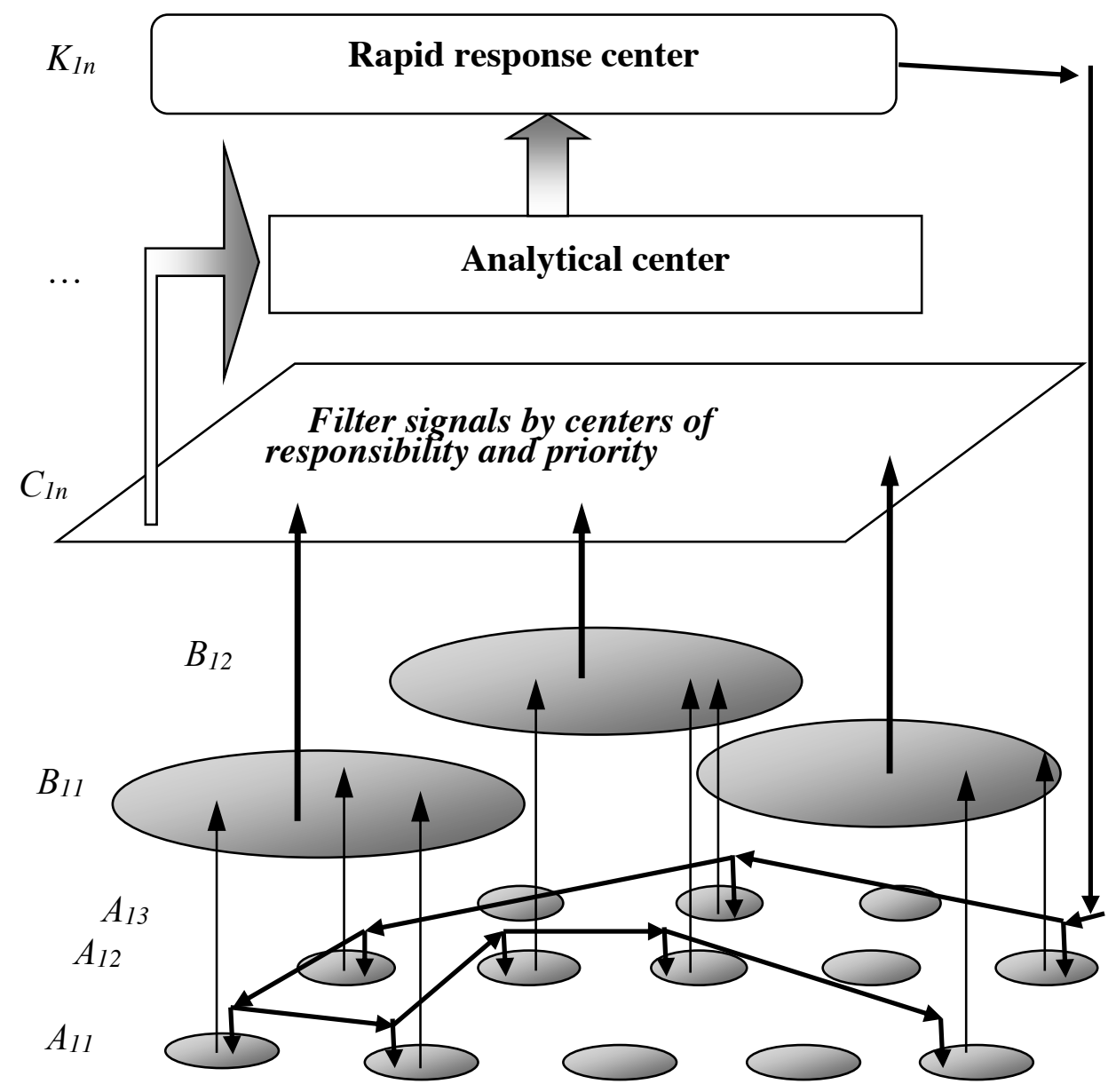

Fig. 1. Signal levels

Figure 1 shows the following designations: the level of occurrence of signals $\left(A_{11}, A_{12}\right.$, $\left.\ldots, A_{1 n}\right)$, the level of reception and accumulation of signals $\left(B_{11}, B_{12}, \ldots, B_{1 n}\right)$, the level of filtering signals $\left(C_{11}, C_{12}, \ldots, C_{1 n}\right)$.

A signal about the presence of a defect (mistakes, errors, inaccuracies) in a BIM model can be seen by constructing a virtual model of a building, rich in information about all elements, including engineering and technological solutions, as well as associated with 
economic data about the object. Having traced the life cycle of an object from the construction stage to the operation stage, the presence of defects that cannot be seen at the design stage will become obvious. In this case, the model allows, avoiding significant costs, the correction of the design error at the initial stage [4].

The paper proposes a model that makes it possible to track signals about defects coming into the system and eliminate them in a timely manner. As shown in Figure 1, signals originate at level $A$ and go to "responsibility centers", which are the respective services involved in implementing the information model.

Next, the signals are filtered by priority. The information flow is directed to the analytical center, where information about defects is processed and transferred to the "response center $»$, which is an integrated service of project developers. So, if a defect in the design of engineering networks is revealed, a signal about possible violations of the operational characteristics of the object, obtained when modeling the stage of operation of the building, is sent to the appropriate design service. It is assisted by an automated system for finding, tracking and directing information flow. Thus, the presented system operates in the " signalresponse » mode.

Let us consider the mechanism of receipt and movement of signals in the quality management system, as well as the system's response to the signal as a multichannel queuing system. Let $I$ be the intensity of signal arrival [5]:

$$
I=\lambda t
$$

where $\lambda$ - frequency of incoming signals to the system; $t$ - defect elimination time.

For a system with expectation, the probability that the channel is free and the reaction to a defect signal will follow immediately is as follows:

$$
P c=\frac{1}{\sum_{n=0}^{N}\left(\frac{I^{n}}{n !}\right)+\frac{I^{N} N}{N !(N-I)}}
$$

where $N$ - the number of defect centers.

The frequency of signals and the probability of their service are the necessary conditions of the problem. A sufficient condition is a mechanism for the qualitative assessment of the strength and significance of the signal. Let $S$ be the signal pulse of the i-th level defect.

$$
S_{i}=\delta_{i} \varphi_{i}
$$

where $\delta$ - the priority level of the signal about the presence of defects; $\varphi$ - an indicator of technological deviation of qualitative features of an object, equal to the ratio of the permissible level of deviation of qualitative features $\varphi_{d}$ to the expected one as a result of the appearance of a defect $\varphi_{d}$ :

$$
\varphi=\frac{\varphi_{d}}{\varphi_{p}}
$$

Let's represent the traffic intensity of signals, taking into account the priority:

$$
I=\lambda t \ln \frac{\delta_{i} \varphi_{d i}}{\varphi_{p i}}
$$


We define the signal strength based on the concept of the physical value of the impulse of force as a vector quantity equal to the product of the force and the time of its action. Signals are prioritized based on the signal strength pulse. Let us denote the signal sulu by $\varphi$. This parameter determines the priority of the level of the primary signal [6].

The average duration of servicing one signal and eliminating a defect is also a random variable $T$ measured in time units.

Suppose that the flow of requirements is Poisson one with the parameter $\lambda_{0}$, requirements are serviced independently, and the service time of each requirement (on each of the $\mathrm{m}$ lines) is exponentially distributed with the parameter $\lambda$. The system must respond to a random defect signal. The service channels of the system may be busy, and there is a possibility of insufficient service or waiting in the system [7].

Let's consider states $k=0,1, \ldots, \mathrm{m}$, where state $k$ means that exactly $k$ service lines are busy. To determine the transitional state of the system from state to state over time $t$, we use a Markov process with discrete states and continuous time [8]. The transition densities are:

$$
\begin{aligned}
& \lambda_{0 j}=\left\{\begin{array}{lll}
\lambda_{0} & \text { at } & j=1 \\
0 & \text { at } & j \neq 1
\end{array}\right.
\end{aligned}
$$

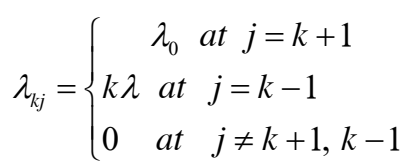

When the next signal arrives in the system during the time $\Delta t$, the system transitions from state $k$ to state $k+1$. The probability of such a transition is $p=\lambda_{0} \Delta t+p(\Delta t)$.

The probability that none of the $k$ busy lines will be vacated during the time $\Delta t$ can be represented as $p^{*}=\left(1-\lambda_{0} \Delta t-p(\Delta t)\right)^{k}$.

Suppose the channels are served independently of each other. In this case, the probability of the release of any line, i.e. the transition of the system state from $k$ to $k+1$, will be determined as follows:

$$
p=1-\left(1-\lambda_{0} \Delta t-p(\Delta t)\right)^{k}=k \lambda \Delta t+p(\Delta t)
$$

The probability of other changes in the system over the time interval $\Delta t$ is $p \Delta t$. Stationary probabilities $\mathrm{p}_{\mathrm{j}}{ }^{*}(\mathrm{t})$ can be found from the equations:

$$
\begin{gathered}
-\lambda_{0} p_{0}^{*}+\lambda p_{1}^{*}=0 \\
-\lambda_{0} p_{k-1}^{*}-(\lambda+k \lambda) p_{k}^{*}+(k+1) \lambda p_{k+1}^{*}=0, \quad 1 \leq k \leq m \\
-\lambda_{0} p_{m-1}^{*}+m \lambda p_{m}^{*}=0
\end{gathered}
$$

From the equations we obtain that

$$
p_{k}=\frac{\frac{1}{k !}\left(\frac{\lambda_{0}}{\lambda}\right)^{k}}{\sum_{m=0}^{M} \frac{1}{m !}\left(\frac{\lambda_{0}}{\lambda}\right)^{m}}, \quad k=0,1, \ldots, m
$$

Next, consider the problem of predicting the quality of a designed object based on an assessment of individual fragments and their compliance with the required quality level. 
Design errors, as mentioned earlier, are detected at subsequent stages of building an information model and signal the magnitude of deviations from a given or standard level. In this case, the errors may not be significant enough to rebuild the model. It is at this stage that the significance of the defect signal is determined. The next proposed model makes it possible to differentiate defects not only by the centers of responsibility, i.e. by the respective services and performers, but also by the degree of importance.

For this, the information model is fragmented into separate structural elements and components, including elements of engineering equipment, technological schemes, logistic subsystems and economic indicators.

Let the confidence probability of deviation from the given quality parameter be determined at the level of $90 \%$. A descriptive model for predicting quality parameters is shown in Fig. 2.

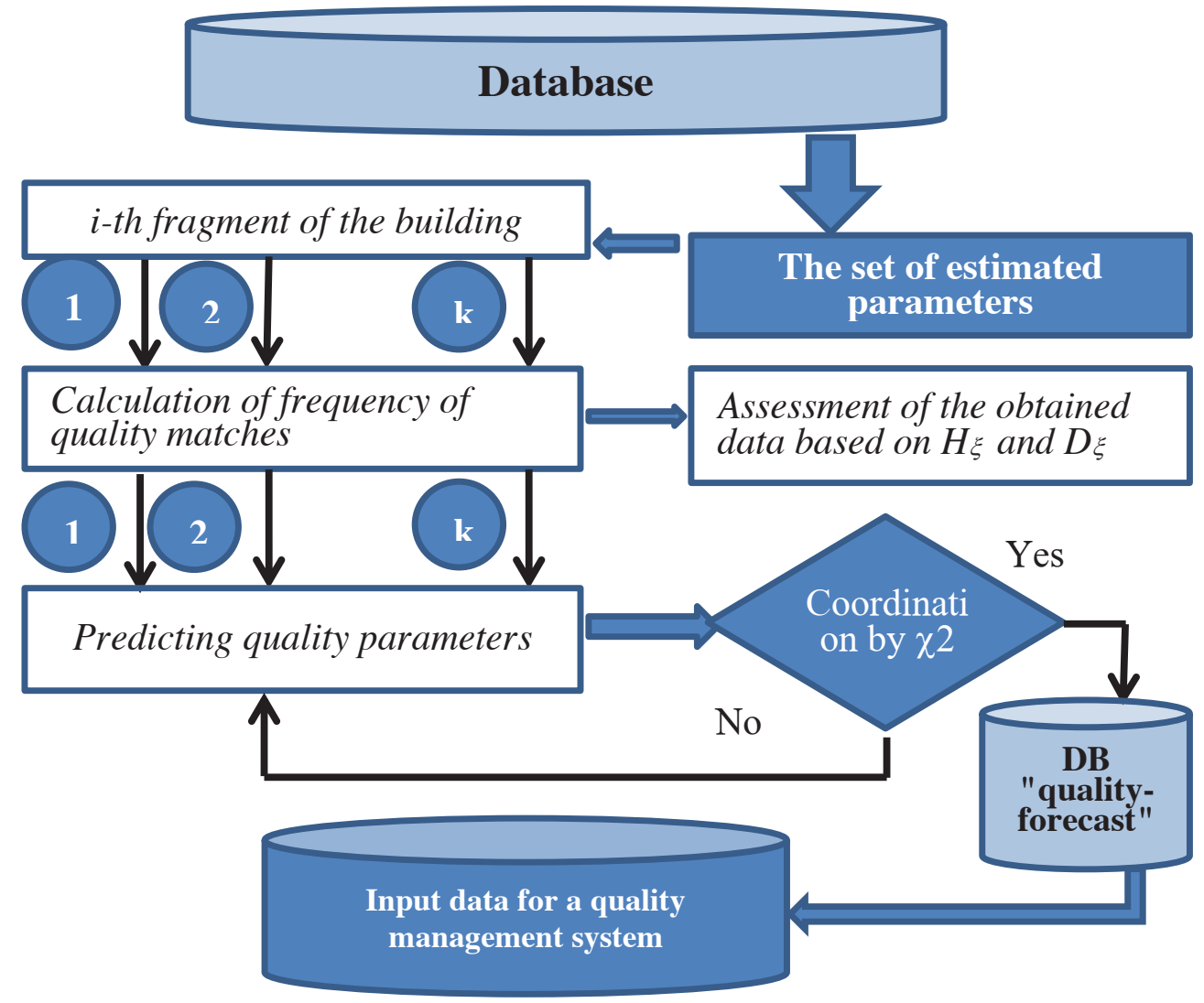

Fig. 2. Descriptive model for predicting the quality of the designed object

As the initial data, we use a sample of fragments of an object of a certain quality for the $\mathrm{j}$-th stage of building a design model, the characteristics of which are [4]:

- quality parameters of the fragment of the object $h_{i}$, defined for the j-th stage

$$
h_{i}=h_{1}+h_{2}+h_{3}+h_{4}+\ldots . .+h_{\mathrm{m}}
$$

where $h_{1} ; h_{2} ; h_{3} ; \ldots h_{m}$ - the number of discrepancies in quality parameters for quality criteria $1,2,3 \ldots . \mathrm{m}$, respectively; 
- characteristics of the design stage of the facility, ensuring the creation of the next fragment of the building $\left(a_{i}, b_{i}\right)$;

- the dynamics of building a model in the area of the $i$-th fragment of building $j$ in a given period.

The problem is solved based on the FOREL class taxonomy algorithm. As a taxon, we define a structural element or node of a designed building (fragment of a BIM model) $i$, the qualitative characteristics of which deviate from the given ones in the course of future dynamic modeling [9].

Let us introduce the coordinates of the center $\mathrm{C}_{\mathrm{j}}$. The sum of the distances $\rho\left(\mathrm{C}_{\mathrm{j}}, n_{i}\right)$ between the center $N$, points $n_{i}$ ( $n_{i}$ is the number of matches to the quality parameters) of this taxon is:

$$
\rho_{j}=\sum \rho\left(C_{j}, n_{i}\right)
$$

where $i=1 \div N$, and the sum of such internal distances for all taxa $F=\sum \rho_{j}$. It is necessary to find such a division of $N$ objects into $n$ taxa so that the above value $F \rightarrow \min$. As a result, a set of taxa is formed equal to the number of studied fragments of model $i$. Now, for each $i$ th object, we build a statistical series to determine the probability of design with quality parameters $h_{1} ; h_{2} ; h_{3} ; \ldots h_{m}$.

Table 1. Statistical series of the $i$-th object by quality parameters

\begin{tabular}{|c|c|}
\hline Sample number & Quality parameters (actual/required) \\
\hline 1 & 0.7 \\
2 & 1 \\
3 & 0.8 \\
$\ldots$ & $\ldots$ \\
$n_{i}$ & 0.3 \\
\hline
\end{tabular}

Parameters for assessing the quality of an object are in the range $[0 \ldots \ldots 1]$ and $\left(h_{l} ; h_{2}\right.$; $\left.h_{3} ; \ldots h_{m}\right)$, respectively. Let's calculate the frequency of obtaining quality assessments $[0 \ldots \ldots 1]$ for the $\mathrm{i}$-th $\mathrm{j}[10]$. These frequencies are:

$$
h_{1}^{*}=\frac{n_{1}}{n_{i}} ; h_{2}^{*}=\frac{n_{2}}{n_{i}} ; h_{3}^{*}=\frac{n_{3}}{n_{i}} ; \ldots ; h_{m}^{*}=\frac{n_{m}}{n_{i}} .
$$

Having determined the frequencies, we build a statistical series (Table 2).

Table 2. Statistical series of the $i$-th object

\begin{tabular}{|c|c|c|c|c|c|c|}
\hline Estimate & 0 & 0.2 & 0.4 & 0.6 & 0.8 & 1 \\
\hline$n_{i}$ & $n_{1}$ & $n_{2}$ & $n_{3}$ & $n_{4}$ & $n_{5}$ & $n_{m}$ \\
\hline$p_{\mathrm{i}}{ }^{*}$ & $p_{1}{ }^{*}$ & $p_{2}{ }^{*}$ & $p_{3}{ }^{*}$ & $p_{4}{ }^{*}$ & $p_{5}{ }^{*}$ & $p_{\mathrm{m}}{ }^{*}$ \\
\hline
\end{tabular}

Let $p^{*}$ be a random variable distributed according to the normal law with parameters

$$
m_{p^{*}}=p ; \sigma_{p^{*}}=\sqrt{\frac{p q}{n}}
$$

where $q=1-p$. 
Let $\beta$ be the confidence probability. We define such an interval $\left(P-\sum \beta ; P+\sum \beta\right)$, that value $p^{*}$ fell into this interval with probability $\beta$.

$$
P\left(\left|p^{*}-p\right|<\sum \beta\right)=\beta
$$

Since value $p^{*}$ are distributed normally, then

$$
P\left(\left|p^{*}-p\right|<\sum \beta\right)=2 \Phi^{*}\left(\frac{\mathrm{E}_{\beta}}{\sigma_{p^{*}}}\right)-1=\beta
$$

from where it follows that

$$
E_{\beta}=\sigma_{p} \operatorname{arq} \Phi^{*}\left(\frac{1+\beta}{2}\right)
$$

Let us introduce the notation $t_{\beta}=\operatorname{arq} \Phi+\left(\frac{1+\beta}{2}\right)$, then $\left|p^{*}-p\right|<t_{\beta} \sqrt{\frac{p q}{n_{0}}}$ (with probability $\beta)$. Confidence interval for probability $p: I_{\beta}=\left(p_{1}, p_{2}\right)$, where $p_{1}=p^{*}-t_{\beta} \sqrt{\frac{p^{*}\left(1-p^{*}\right)}{n}}$ - lower limit of the confidence interval;

$p_{2}=p^{*}+t_{\beta} \sqrt{\frac{p^{*}\left(1-p^{*}\right)}{n}}$ - upper limit of the confidence interval.

Let us determine the probability of designing the $i$-th object, a fragment of the BIM model, with quality parameters $\left(h_{1} ; h_{2} ; h_{3} ; \ldots h_{m}\right) \in[0 \ldots \ldots 1]$. The mathematical expectation and standard deviation for this value will be:

$$
\begin{aligned}
& m_{\chi}=\sum_{i=1}^{k} \chi_{i}-p_{i}=p_{1}^{*}+2 p_{2}^{*}+3 p_{3}^{*}+4 p_{4}^{*}+5 p_{5}^{*}+m p_{m}^{*}, \\
& \sigma=\sqrt{D_{x}^{2}}=\sqrt{m^{2} p_{m}+25 p_{5}+16 p_{4}+9 p_{3}+4 p_{2}+p_{1}} .
\end{aligned}
$$

Distribution function:

$$
\Phi^{*}(x)=\frac{1}{\sqrt{2 \pi}} \int_{-\infty}^{\infty} e^{-\frac{1}{2} t^{2}} d t
$$

The probability of design with quality parameters $\left(h_{1} ; h_{2} ; h_{3} ; \ldots h_{m}\right)$ is calculated as follows:

$$
\underset{i=1,2,3,4,5, m}{P_{i}}=\Phi^{*}\left(\frac{X_{i}-m_{x}}{\sigma}\right)=\Phi^{*}\left(\frac{\chi_{i}-m p_{m}^{*}-5 \rho_{5}^{*}-4 \rho_{4}^{*}-3 \rho_{3}^{*}-2 \rho_{2}^{*}-\rho_{1}^{*}}{5 \rho_{5}^{*}+4 \rho_{4}^{*}+3 \rho_{3}^{*}+2 \rho_{2}^{*}}\right)
$$

Let's define the parameters of the design quality [11].

High quality design:

$$
P_{m}=\Phi^{*}\left(\frac{m-m p_{m}^{*}-5 \rho_{5}^{*}-4 \rho_{4}^{*}-3 \rho_{3}^{*}-2 \rho_{2}^{*}}{m p_{m}^{*}+5 \rho_{5}^{*}+4 \rho_{4}^{*}+3 \rho_{3}^{*}+2 \rho_{2}^{*}}\right)
$$


Satisfactory design quality:

$$
P_{4}=\Phi^{*}\left(\frac{4-5 \rho_{5}^{*}-4 \rho_{4}^{*}-3 \rho_{3}^{*}-2 \rho_{2}^{*}}{5 \rho_{5}^{*}+4 \rho_{4}^{*}+3 \rho_{3}^{*}+2 \rho_{2}^{*}}\right)
$$

Poor design quality:

$$
P_{3}=\Phi^{*}\left(\frac{3-5 \rho_{5}^{*}-4 \rho_{4}^{*}-3 \rho_{3}^{*}-2 \rho_{2}^{*}}{5 \rho_{5}^{*}+4 \rho_{4}^{*}+3 \rho_{3}^{*}+2 \rho_{2}^{*}}\right)
$$

Many design defects:

$$
\begin{gathered}
P_{2}=\Phi^{*}\left(\frac{2-5 \rho_{5}^{*}-4 \rho_{4}^{*}-3 \rho_{3}^{*}-2 \rho_{2}^{*}}{5 \rho_{5}^{*}+4 \rho_{4}^{*}+3 \rho_{3}^{*}+2 \rho_{2}^{*}}\right) \\
p_{m}+p_{5}+p_{4}+p_{3}+p_{2}+p_{1}=1 .
\end{gathered}
$$

Thus, forecasting the quality of design using BIM technology consists in determining the quality parameter for an individual building element.

\section{Discussion}

BIM is based on the possibility of comparing current design solutions for given quality parameters with predicted ones, which can have significant qualitative changes during the construction of a building or in the conditions of further operation.

The disadvantage of the model is that it is reliable only for the normal distribution of a random variable. In case of significant deviations of the qualitative parameters, it is necessary to apply the mechanisms of the exponential distribution law or Erlang's law.

Taking into account the characteristics of technical information as modeling conditions when predicting the quality of design solutions allows getting a more reliable result. The initial information that saturates the BIM model should be subjected to deep and comprehensive analysis in order to exclude design errors as much as possible. The influence of each additional factor taken into account is statistically significant, and the standard error decreases.

When designing according to the BIM model, load-bearing structures are usually tested in virtual mode for various types of loads. The study allows providing the necessary margin of safety for the building, ensuring its stability and safe operation in various conditions This is especially important when operating facilities under conditions of seismic activity, increased dynamic loads, and in aggressive environments [11].

The information model allows for a numerical study of a building while maintaining a high object identity. The mathematical apparatus embedded in the software of the BIM model allows exploring the building in a virtual format in almost any situation, including emergency. The model also makes it possible to make capacity calculations for flat beamless slabs, calculations for soil deformation, and calculation of metal structures. The speed of the analysis of the results and the correction of the cross-sections based on the results of the calculations gives the designer the opportunity to solve a wide range of problems when analyzing the operation of the structure. For example, you can calculate a building in geometric nonlinearity in a direct dynamic setting on an assembled structure.

In this case, a report on the test of the structure can be issued with links to the relevant paragraphs of the regulatory documentation. Based on the obtained calculation results, the 
obtained model is synchronized. This model allows avoiding overspending of expensive building materials and making the right investment decision.

\section{Conclusion}

BIM opens a new era in construction. In view of the complexity and versatility of the presented technology, we can say with confidence that BIM is not just a model, it is a complex process that covers not only construction, but also includes elements of the external environment. BIM is a complex digital design of an object that allows you to dynamically trace the mechanisms of functioning of internal systems in conjunction with the external space, including road networks and utilities, as well as the external architectural landscape. It is a digital dynamic system that includes methods for constructing logistic structures, work schedules and determines the most rational solutions, both engineering and economic ones.

But the most important thing is that this innovative building design technology allows seeing the entire life cycle of a building from the design stage to the operation stage, seeing possible errors and inaccuracies that cannot always be identified during design, but ultimately can lead to serious disruptions during the operation of the facility.

To enable timely detection of design errors, a model for signaling the presence of defects has been developed, and a mechanism for assessing the degree of their significance for the project has been proposed. The model also provides for stochastic analysis of the deviation of the signs of defects, i.e. it determines the magnitude of possible deviations of the final results from the given parameters of the designed object. Information modeling makes it possible not only to build spatial models, but to see the result of the subsequent operation of the facility, which is especially important when designing large industrial complexes saturated with complex technological equipment. The BIM model makes it possible to see the work of the building's engineering systems and eliminate the problems that arise at the design stage.

Ultimately, BIM allows you to quickly determine the possible options for the implementation of the project, eliminate errors at the design stage and choose the best option, taking into account the real construction conditions and possible restrictions.

\section{References}

1. E. Okolelova, M. Shibaeva, N. Trukhina, Model of investment appraisal of high-rise construction with account of cost of land resources 2018 E3S Web of Conferences, 03014 (2018)

2. V. N. Barinov, E. Yu. Okolelova, N. I. Truhina, O. V. Kornickaya, Upravlenie gorodskimi territoriyami: ucheb. Posobie, 127 («Ritm», Voronezh, 2020)

3. O. V. Kornickaya, E. Yu. Okolelova, N. I. Truhina, Razvitie innovacij i mekhanizm ih rasprostraneniya na predpriyatiyah strojindustrii, Upravlenie ekonomicheskimi sistemami: elektronnyj nauchnyj zhurnal, 12(60), 93 (2013)

4. O. V. Caregorodceva, E. YU. Okolelova, Model' prognozirovaniya parametrov kachestva vypuskaemoj produkcii, Nauchno-prakticheskij zhurnal «Sovremennaya ekonomika: problemy i resheniya» red. V. V. Davnisa, 6, 121-130 (Voronezh: Voronezh state university, 2013)

5. P. G. Grabovyj, N. I. Truhina, E. Yu. Okolelova, Dinamicheskaya model' prognozirovaniya razvitiya innovacionnogo proekta, Tekhnologiya tekstil'noj promyshlennosti, 1(367), 78-82 (2017) 
6. E. YU. Okolelova, Modeli investicionnogo prognozirovaniya rynka kommercheskoj nedvizhimosti, red. V. V. Gasilova, 326 (Voronezh, izd-vo «Istoki», 2008)

7. E. Yu. Okolelova, L. V. Shulgina, N. I. Trukhina, M. A. Shibaeva, A. V. Shulgin, The mechanism of evaluation under the conditions of uncertainty of innovational project as a random process. Advances in Intelligent Systems and Computing, 726, 56-63 (2019)

8. E. Okolelova, M. Shibaeva, O. Shalnev, Development of innovative methods for risk assessment in high-rise construction based on clustering of risk factors E3S Web of Conferences, 33, 03015 (2018)

9. M. Shibaeva, O. Shalnev, E. Serebryakova, Efficiency improvement of the investment and innovation activities in the transport facility construction field with public-private partnership involvement, Energy management of municipal transportation facilities and transport - EMMFT 2017 Khabarovsk, Russia, 10-13 april, IOP Conference Series: Earth and Environmental Science, 012170 (2017)

10. E. Yu. Okolelova, O. K. Meshcheryakova, Investicionnye mekhanizmy rynka nedvizhimosti. Ipoteka, Monografiya, 219 (Voronezh, izd-vo «Istoki», 2007)

11. E. Yu. Okolelova, N. I. Truhina, Stroitel'stvo vysotnyh zdanij: ocenka effektivnosti proektov v usloviyah riskov, 136 (Monografiya. Voronezh, VGASU, 2016)

12. G. Kozlov, M. Pushkarev, D. Belyaev, E3S Web of Conferences, 215, 03004 (2020) doi:10.1051/e3sconf/202021503004 